\title{
HISTÓRIA E ARQUEOLOGIA E OS DEBATES SOBRE OS MANUSCRITOS DE QUMRAN
}

\author{
Fernando Mattiolli Vieira ${ }^{1}$
}

\begin{abstract}
Resumo
No ano de 1947, em uma região no deserto da Judeia próxima às margens do mar Morto, foi encontrada uma das mais importantes coleções de manuscritos da Antiguidade, conhecida como Manuscritos de Qumran. Algumas das cavernas em que os manuscritos foram descobertos são próximas de um assentamento antigo e os primeiros pesquisadores deduziram que esses manuscritos haviam sido redigidos naquelas instalações por um grupo religioso judaico. Investigações posteriores, partindo da Arqueologia, viriam a questionar essa tese inicial defendida principalmente por historiadores e se instauraria um debate corrente até os dias atuais. Este artigo faz uma reconstrução historiográfica que apresenta os principais pontos desse debate e propõe que a manutenção dele e a dificuldade de se chegar a um consenso entre a História e a Arqueologia estão relacionadas ao campo epistemológico dessas disciplinas, com destaque ao papel atribuído para as fontes textuais e materiais.
\end{abstract}

\section{Palavras-chaves}

Manuscritos de Qumran; assentamento de Qumran; História; Arqueologia; fontes textuais; fontes materiais.

${ }^{1}$ Professor Adjunto, Universidade de Pernambuco. 


\begin{abstract}
In the year 1947, in a region in the Judean Desert near the shores of the Dead Sea, was found one of the most important collections of ancient manuscripts, known as the Qumran Manuscripts. Some of the caves in which the manuscripts were discovered are close to an old settlement and early researchers deduced that these manuscripts had been written in those facilities by a Jewish religious group. Subsequent investigations, starting from Archeology, would come to question this initial thesis defended mainly by historians and a current debate would be established until today. This article makes a historiographic reconstruction that presents the main points of this debate and proposes that the maintenance of it and the difficulty of reaching a consensus between History and Archeology are related to the epistemological field of these disciplines, with emphasis on the role attributed to the textual and material sources.
\end{abstract}

\title{
Keywords
}

Qumran Manuscripts; Qumran settlement; History; Archeology; textual sources; material sources. 


\section{Os Manuscritos Qumran: entre a História a Arqueologia}

Um dos principais debates entre as disciplinas de História e Arqueologia dos dias atuais está relacionado a um dos mais importantes achados de textos antigos da história: os Manuscritos de Qumran. A descoberta deles ocorreu no ano de 1947, em 11 cavernas de uma área conhecida como Vale de Qumran (Wadi Qumran), distante cerca de 30 quilômetros a sudeste de Jerusalém, entre o deserto da Judeia e a cabeça do mar Morto. ${ }^{2}$ São mais de 900 manuscritos de natureza religiosa com estilos literários variados: exegéticos, haláquicos, poéticos, litúrgicos, entre outros. ${ }^{3}$ Todos eles são textos judaicos, escritos em hebraico (com poucas exceções), que provam estarem relacionados graças ao estilo de escrita e, com base nisso, são datados geralmente entre os séculos II a.C. e I d.C.

A importância dos Manuscritos de Qumran é inestimável. Eles compõem o mais amplo corpus documental daquele período. Contribuíram para diminuir a carência de fontes textuais, sendo associados a outros textos como a Bíblia Hebraica, a Mishná, os dos historiadores contemporâneos Flávio Josefo e Fílon de Alexandria, os dos primeiros grupos judaicocristãos e outros, na busca de uma maior compreensão das dinâmicas internas e relações externas da sociedade judaica sob domínio dos selêucidas e romanos entre o século II a.C. e a destruição do Segundo Templo de Jerusalém em 70 d.C. e o papel social desempenhado pelo grupo redator dos manuscritos. Não se deve deixar de lembrar do impacto produzido por esses textos na história da construção do cânon bíblico. Eles trouxeram à luz tradições desconhecidas do período, mostrando que a diversidade político-religiosa era bem mais ampla do que se conhecia pela historiografia até 1947. Além do mais, foi possível redimensionar a temporalidade da evolução da Bíblia Hebraica, uma vez que esses manuscritos são pelo menos mil anos mais antigos que o texto massorético utilizado como base para as versões modernas da Bíblia - o que possibilitou o retorno para um momento mais "original" da elaboração textual. ${ }^{4}$

\footnotetext{
$2 \mathrm{O}$ conjunto das diversas coleções encontradas na região do mar Morto recebe o nome genérico de Manuscritos do Mar Morto. Para uma introdução sobre essas coleções veja Garcia Martínez, 1995: 15-20.

3 Sobre as tradições e estilos textuais, principalmente dos Manuscritos de Qumran, veja Francisco, 2017.

${ }^{4} \mathrm{O}$ texto medieval mais antigo e completo conhecido é o Códice de Leningrado, utilizado para as Bíblias hebraicas atuais. Para exemplos que mostram as variantes do texto bíblico, ver García Martínez, 2017 e Francisco, 2017.
} 
A grande maioria das pesquisas sobre os Manuscritos de Qumran tem seus objetos extraídos do conteúdo dos textos. As centenas de manuscritos foram utilizadas para a elaboração de uma miríade de temas e a produção bibliográfica em nível mundial continua aquecida mesmo depois desses achados terem completado 70 anos de vida moderna. ${ }^{5}$ No entanto, entre todos esses temas, nenhum gerou mais controvérsia na historiografia dos manuscritos que o que se refere à relação entre eles e um assentamento próximo às cavernas em que foram encontrados. Essa área da pesquisa trata pouco do conteúdo dos manuscritos e tem como preocupação maior compreendê-los como suportes da escrita e contextualizá-los com base na cultura material do período.

Façamos um breve resumo sobre a história desse assentamento e sua relação com os manuscritos. O conjunto dos edifícios é conhecido pelo nome árabe Khirbet Qumran, que pode ser traduzido como Ruínas de Cinzas. Os registros da presença humana no entorno dos edifícios são muito antigos, datando de períodos pré-históricos. As cavernas próximas foram utilizadas esporadicamente em todos os períodos - fato ligado à ocupação de áreas não tão distantes e mais bem consolidados na região, como Jericó e ‘Ein Gedi (Mizzi, 2017: 66). Os primeiros edifícios em Qumran foram erguidos provavelmente no final do século VIII a.C. ou início do século VII a.C. e permaneceram, com poucas alterações, até a destruição do Primeiro Templo de Jerusalém, no século VI a.C. A área escolhida foi muito propícia, com uma topografia razoavelmente plana e elevada que proporcionava uma proteção natural e em que a captação de água era feita com relativa facilidade (comparando com outras áreas da região) e próxima às importantes tamareiras, características da região do mar Morto, que compunham uma fonte natural para a produção industrial (Magen, Peleg, 2007: 24).

\footnotetext{
5 Um projeto de levantamento dessa bibliografia é conduzido por profissionais do Orion Center, ligado ao Instituto de Estudos Judaicos da Universidade Hebraica de Jerusalém. O acervo conta sobretudo com publicações produzidas a partir da década de 1990, quando houve um aumento exponencial da produção bibliográfica sobre os Manuscritos do Mar Morto em geral. Com os dados disponibilizados nesse projeto é possível acompanhar parte do ritmo das publicações e as temáticas abordadas. Disponível em http:/ / orion.mscc.huji.ac.il/resources/bib/current.shtml (último acesso: 22/01/2020).
}

Heródoto, Unifesp, Guarulhos, v. 4, n. 2, 2019.2 p. 283-305

DOI: $10.34024 /$ herodoto.2019.v4.10976 


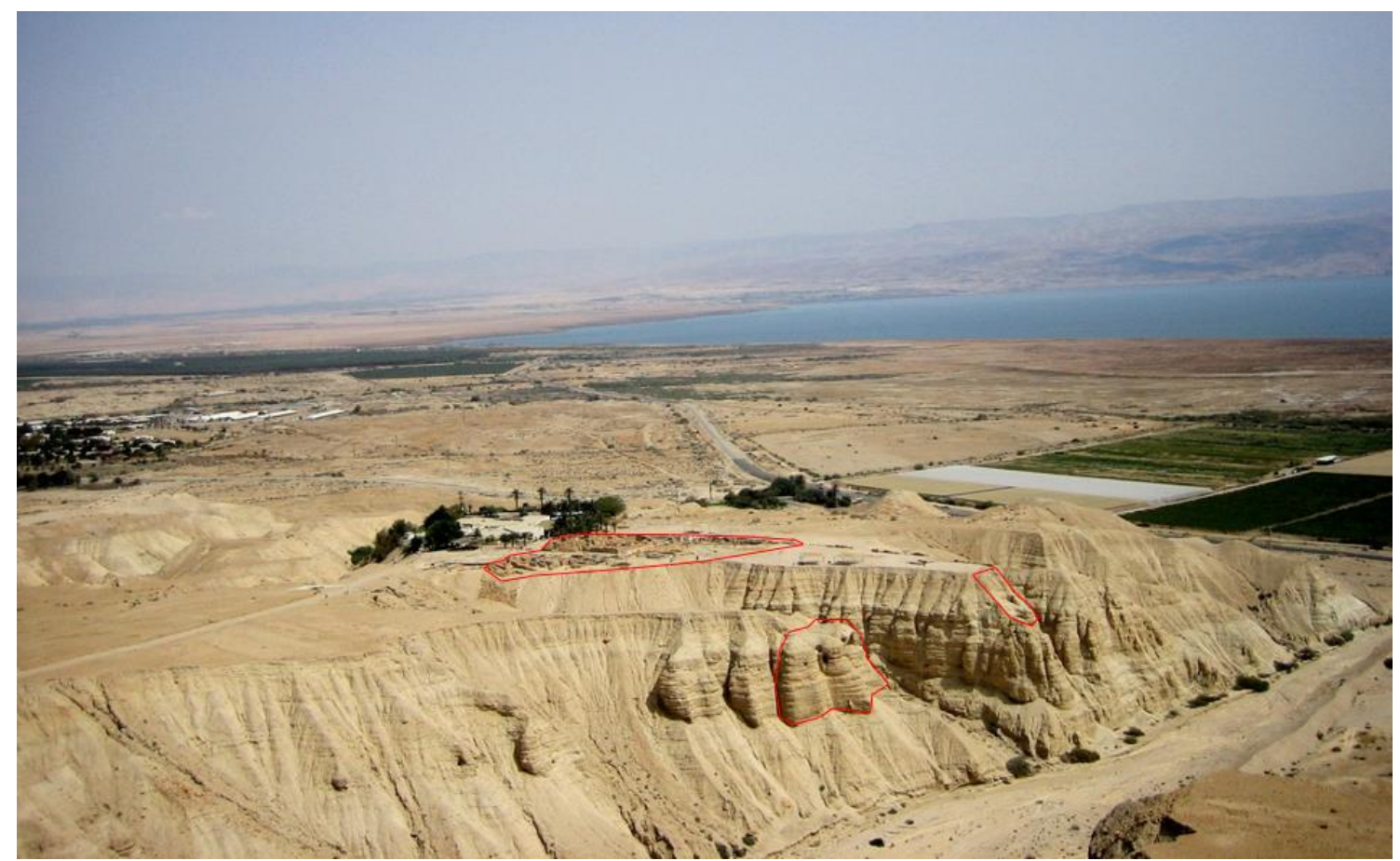

Figura 1: Imagem panorâmica que mostra as ruínas de Qumran ao centro. Abaixo estão as cavernas 4-5 (esquerda), 7-10 (direita), as mais próximas do assentamento, e ao fundo o mar Morto (arquivo pessoal).

O estabelecimento da "vila de Qumran" durante esse período esteve ligado a um movimento de ocupação das terras ao sul de Jerusalém, no deserto da Judeia e no vale do Jordão, resultante da destruição do Reino do Norte, com capital em Samaria, promovida pelos assírios em 720 a.C. (2 Reis 17:24). Um contingente populacional veio a se estabelecer nessas regiões na condição de refugiados (Jeremias 41:5; 2 Crônicas 30:10-11, 34:9, Finkelstein, 2018: 206). ${ }^{6} \mathrm{O}$ deslocamento dessas populações do norte para as regiões do sul deixou marcas culturais importantes, com tradições nortistas que foram incorporadas ao cânon bíblico que conhecemos (Schniedewind, 2011: 110-115).

Posteriormente, no século VI a.C., Qumran teve parte de sua estrutura destruída durante a campanha de conquista dos babilônios contra os judeus e a vila ficou desabitada por séculos, até que voltaria a ser ocupada e ter sua estrutura original ampliada nos períodos helenístico e romano, durante o século II a.C. e o início do século I a.C. Essa fase de ocupação

\footnotetext{
${ }^{6}$ Entre o final do séc. VIII a.C. e início do séc. VII a.C. houve uma mudança significativa na ocupação dessas regiões, comprovada pelo estabelecimento de uma série de assentamentos de características similares, com destaque às possibilidades de aproveitamento da água da chuva e corredeiras. Segundo Magen e Peleg, nenhum desses assentamentos foi de colonização oficial, nem militar, comercial ou agricultor (2007: 24).
}

Heródoto, Unifesp, Guarulhos, v. 4, n. 2, 2019.2 p. 283-305

DOI: $10.34024 /$ herodoto.2019.v4.10976 
regular duraria até 68 d.C., quando suas instalações foram novamente destruídas, dessa vez pelos romanos, durante a Primeira Revolta Judaica (66-74 d.C.). No entanto, a presença de vestígios materiais mostra que o sítio foi ocupado por curtos períodos e visitado durante os períodos romano, bizantino e otomano. Exploradores do século XIX deixaram informações sobre o local soterrado. Por fim, o sítio é "redescoberto" em virtude do interesse criado logo após a descoberta dos manuscritos nas cavernas de Qumran em 1947.

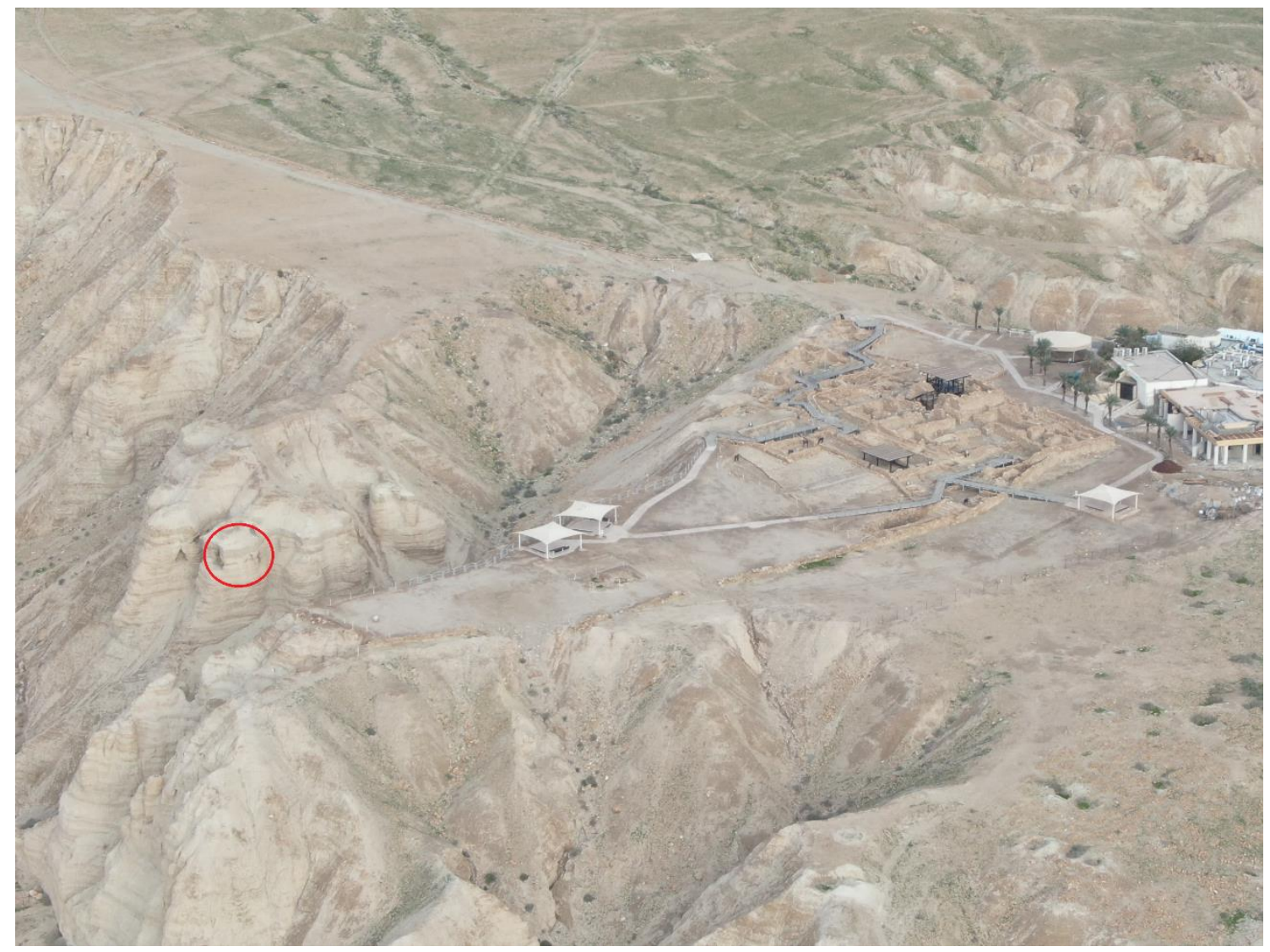

Figura 2: Vista aérea a leste do assentamento. Note a caverna 4 à esquerda, apelidada por alguns pesquisadores como "biblioteca de Qumran" por abrigar quase 600 manuscritos (foto de Elyahu Valdman; uma cortesia do Departamento de Arqueologia da Administração Civil da Judeia e Samaria, Israel).

Da condição de ignorado pelos pesquisadores até então, o sítio de Qumran desponta como peça chave para a compreensão da história dos manuscritos. A conexão entre ele, as cavernas, os manuscritos e a identidade de seus autores é feita primeiramente pelo arqueólogo israelense Eleazar Lipa Sukenik, em 1948 após ter acesso a alguns manuscritos vendidos por beduínos clandestinamente. O comentário que mais bem sintetiza sua ideia é este:

[...] eu tenho encontrado alguma indicação que tem me encorajado a oferecer uma hipótese sobre esse assunto. Quando examinei os pergaminhos... encontrei em 
um deles um tipo de livro de regulamentos para a conduta de membros de uma irmandade ou seita. Eu me inclino à hipótese de que esse depósito de manuscritos pertenceu originalmente à seita dos essênios, como, segundo é conhecido de diferentes fontes literárias, o local de assentamento deste grupo sectário sendo ao lado ocidental do mar Morto, nas proximidades de Engedi (1948: 16).

Sukenik tinha conhecimento das chamadas "fontes clássicas", um pequeno conjunto sinótico de registros literários que descreve o comportamento religioso de um grupo judaico conhecido como "essênios" (do grego essenoi). Essas fontes são textos do historiador judeu Flávio Josefo (Guerra Judaica 2.119-161; Antiguidades Judaicas 18.18-22), do historiador e filósofo judeu-egípcio Fílon de Alexandria (Toda Boa Pessoa é Livre 75-91; Apologia dos Judeus 11) e do historiador e naturalista romano Plínio Velho (História Natural 5.73). Sukenik comparou um manuscrito encontrado na caverna 1, chamado Regra da Comunidade (1QS), com as fontes clássicas e concluiu que os manuscritos haviam pertencido àqueles judeus essênios. Mais do que isso: afirmou também que foram eles que habitaram as instalações de Qumran e que depositaram os manuscritos nas cavernas.

Dentre as descrições das fontes clássicas consideradas por Sukenik, a mais "objetiva" é a pequena nota que Plínio faz ao descrever a região do mar Morto:

On the west side of the Dead Sea, but out of range of the noxious exhalations of the coast, is the solitary tribe of the Essenes, which is remarkable beyond all the other tribes in the whole world, as it has no woman and has renounced all sexual desire, has no money, and has only palm-trees for company. Day by day the throng of refugees is recruited to an equal number by numerous accessions of persons tired of life and driver thither by the waves of fortune to adopt their manners. [...] Lying below the Essenes was formerly the town of Engedi, second only to Jerusalem in the fertility of its land and in its groves of palm-trees [...] (História Natural 5.73).

A perícope pliniana não apenas registra a existência de um grupo de judeus essênios, mas também o localiza entre as cidades de ‘Ein Gedi, ao sul da orla oeste do mar Morto, e Jericó (que devia se localizar em algum ponto entre os cerca de 39 quilômetros de extensão da orla). Somando essa descrição com outros paralelos entre as fontes clássicas e os manuscritos, Sukenik constrói uma tese que servirá como paradigma epistemológico nas pesquisas dos manuscritos a partir de então: a junção entre os Manuscritos de Qumran, a identidade de seus autores (essênios) e o espaço físico que haviam ocupado (Qumran). Embora Sukenik fosse o arqueólogo israelense mais proeminente de seus dias, ele chegou a essa conclusão baseando-se 
apenas nas fontes textuais, antes mesmo que fosse feita qualquer investigação ordenada no sítio ou nas cavernas. ${ }^{7}$

A primeira série extensiva de escavações do assentamento ocorreu entre os anos 1951 e 1956, comandada pelo arqueólogo francês Roland de Vaux (da Escola Bíblica e Arqueológica Francesa de Jerusalém) e o arqueólogo britânico Gerald Lankester Harding (do Departamento de Antiguidades da Jordânia). De Vaux, o mais proeminente deles, também conhecia os essênios das fontes clássicas e, segundo a historiografia das escavações, já se encontrava convencido de que Qumran havia sido o local de habitação da comunidade dos manuscritos. ${ }^{8}$ Nas escavações, de Vaux encontrou um jarro cilíndrico similar aos que abrigavam os manuscritos nas cavernas de Qumran (1953: 105). Com essa evidência material, "independentemente" da relação estabelecida previamente com base nas fontes textuais, havia agora a comprovação arqueológica da relação entre os manuscritos, as cavernas e o sítio de Qumran. A partir de então, por duas "frentes", ou seja, através das fontes textuais e materiais, chegava-se a uma síntese comum.

De Vaux utilizou as fontes clássicas e os manuscritos como guias para suas escavações. Ele concluiu que aquele lugar foi ocupado por um grupo religioso "sectário", asceta, celibatário e de práticas austeras, promovendo inclusive uma espécie de "arqueologia sectária", considerando, por exemplo, que a falta de opulência dos edifícios seria indício de que aquele grupo era desprendido de ideais de riqueza ou luxúria (como descrito em alguns manuscritos) e ao batizar uma das salas do assentamento como scriptorium, local em que, supostamente, os manuscritos eram redigidos e/ ou copiados pelos essênios (1973).

Por fim, em um período que abrangeu uma década, a hipótese explicativa sobre o sítio de Qumran foi canonizada e pareceu suficiente para os pesquisadores, fossem eles arqueólogos ou (principalmente) historiadores. Em 1958, o historiador bíblico Frank Moore Cross, talvez o mais respeitado acadêmico memorado na historiografia dos manuscritos, já se encontrava plenamente convencido por essa hipótese (1958). Tempos depois, ele elabora a máxima que seria reiterada inúmeras vezes pelas gerações seguintes de pesquisadores:

\footnotetext{
7 Outros, historiadores como William Hugh Brownlee e André Dupont-Sommer, que estiveram diretamente ligados aos manuscritos em suas instituições de pesquisas, defenderam a mesma tese de Sukenik pouco depois (1950).

${ }^{8}$ Embora em 1949 os dois arqueólogos tenham feita uma escavação pouco extensiva e concluído que os edifícios de Qumran eram de um forte romano dos séculos II d.C. ou III d.C.
} 
O estudioso que "tivesse receio" de identificar a seita de Qumran com os essênios se colocaria numa posição espantosa: deveria propor seriamente que duas facções importantes criaram grupamentos comunais na mesma região do deserto em torno do mar Morto e viveram efetivamente lado a lado durante dois séculos, esposando as mesmas opiniões estranhas, cumprindo atos de purificação, refeições rituais e cerimônias semelhantes ou praticamente iguais. Ele deveria supor que uma delas, descrita em detalhes por autores clássicos, desapareceu sem deixar vestígios de suas construções ou mesmo restos de utensílios de cerâmica; da outra, sistematicamente ignorada pelas fontes clássicas, restaram extensas ruínas e até mesmo uma grande biblioteca. Eu prefiro ser afoito e categoricamente identificar os homens de Qumran com seus permanentes convivas, os essênios (1973: 331-332).

Se o conhecimento é um fim que pode ser construído por diferentes perspectivas, a hipótese desvelada para explicar a relação dos manuscritos com Qumran é um exemplo que apresenta a História e a Arqueologia como meios, ciências que foram capazes de prover ajuda mútua para alcançar uma conclusão comum. Contudo, o desenvolvimento desses campos científicos fez com que essa relação harmoniosa fosse abalada não muito tempo depois.

\section{A Arqueologia na vanguarda das contestações}

O que uso denominar como "tríade de Qumran", conceito que encerra a interdependência entre os Manuscritos de Qumran, a identidade de seus autores e o local em que habitaram, ${ }^{9}$ manteve-se como um paradigma inquestionável por pouco mais de uma década tanto para a História quanto para a Arqueologia. Essa convivência anuente sofreria sua primeira ranhura em 1960, partindo da Arqueologia. O arqueólogo alemão Karl Heinrich Rengstorf foi o responsável pela primeira tese discordante, afirmando que os manuscritos não poderiam ter sido redigidos em Qumran, mas que haviam sido trazidos da biblioteca do Templo de Jerusalém antes da destruição pelos romanos e depositados nas cavernas de Qumran (1960). ${ }^{10}$

Após Rengstorf, várias teses foram elaboradas por arqueólogos para explicar qual a proveniência dos manuscritos e o que foi Qumran.

\footnotetext{
9 Para a Arqueologia, esse conceito pode ser redimensionado. A questão da identidade dos qumranitas é mais desprezada, enquanto as cavernas assumem posição de destaque. Assim, a tríade de Qumran para a Arqueologia compreenderia na relação entre os manuscritos (como suportes da escrita), o assentamento e as cavernas.

${ }^{10}$ Essa opinião será conhecida no Brasil através do teólogo Gaudêncio Gratzfeld (1961: 417), que concordará com a ideia central de Rengstorf.
}

Heródoto, Unifesp, Guarulhos, v. 4, n. 2, 2019.2 p. 283-305

DOI: $10.34024 /$ herodoto.2019.v4.10976 
Apresentemos alguns exemplos. Pauline Donceel-Voûte e Robert Donceel acreditam que Qumran foi uma espécie de "vila", similar às vilas romanas utilizadas periodicamente por famílias abastadas de Jerusalém. Para ela e ele, as evidências materiais presentes no assentamento não correspondem com as de um grupo religioso que desprezava a riqueza (1994: 1-38). Yizhar Hirschfeld afirma que Qumran foi uma fortaleza durante o período asmoneu (140-37 a.C.), e depois, com a presença romana na região e a perda de sentido de sua função militar, tornou-se uma propriedade agrícola (2004). ${ }^{11}$ Magen e Peleg, que conduziram a mais extensiva campanha de escavações em Qumran (1993-2004) depois de de Vaux, concluíram, como Hirschfeld, que o local foi inicialmente uma guarnição asmoneia que tinha como objetivo proteger a região de infiltrações de vizinhos rivais pelo sudeste da Judeia (uma torre no assentamento explicaria a função militar), mas que após a intervenção direta dos romanos no poder político da Judeia (37 a.C.) o local teria se tornado um centro produtor de cerâmica (2006: 49). A conclusão deles, após 11 anos de escavações em Qumran, é bastante contestadora:

\begin{abstract}
A associação entre Qumran, as cavernas e os manuscritos é uma hipótese em que falta qualquer base arqueológica, embora seja bastante conveniente para todas as partes relacionadas, tanto historiadores quanto arqueólogos. Qualquer que separe essa relação, da comunidade essênia e os manuscritos encontrados nas cavernas, necessariamente mina também todas as ideias anteriores sobre a natureza e a proveniência dos manuscritos. A comunidade acadêmica ainda não está preparada para uma revolução [...]. A teoria que liga o sítio aos manuscritos tem sobrevivido durante tanto tempo apenas porque é bastante conveniente (2007: 64).
\end{abstract}

Além dessas, várias outras hipóteses se fazem presentes na historiografia de Qumran e dos manuscritos (Mizzi, 2017).

\footnotetext{
${ }^{11} \mathrm{O}$ autor terá uma série de desafetos com uma companheira de profissão, a especialista em arqueologia do Oriente Médio, Jodi Magness. Seus pontos de atrito estão relacionados ao método investigativo e às conclusões. Diferentemente de Hirschfeld, a arqueóloga acredita que uma comunidade ascética essênia habitou o assentamento de Qumran.
} 


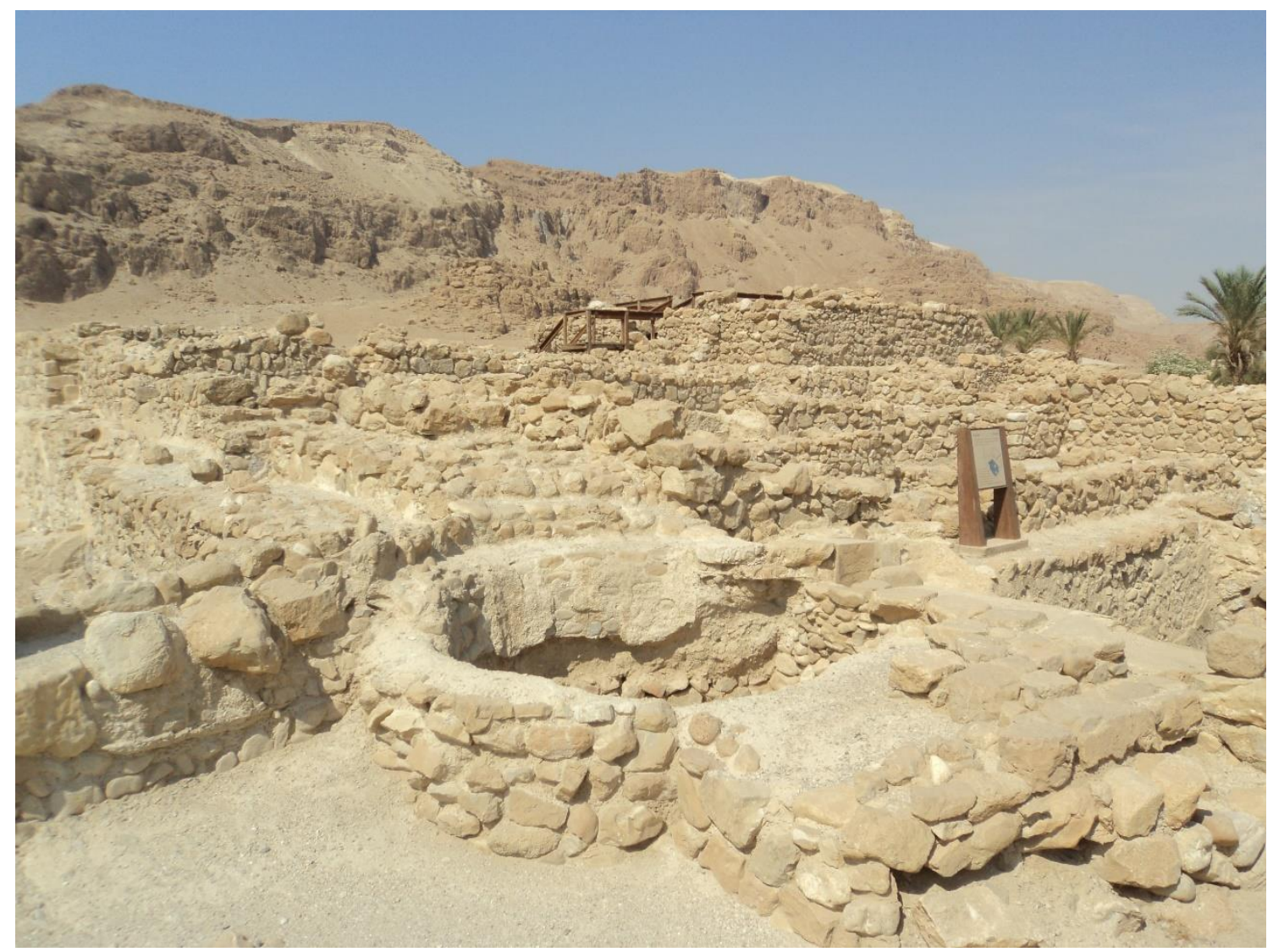

Figura 3: Ao fundo, torre noroeste do assentamento. Note que sua base segue um padrão de inclinação utilizada em estruturas militares. À frente, cisterna que fazia parte do sistema de abastecimento do complexo (arquivo pessoal). ${ }^{12}$

A crítica inicial dos arqueólogos reside no campo metodológico. A conclusão de que um grupo religioso judaico residiu em Qumran e aí redigiu ao menos parte de seus manuscritos antecipou qualquer investigação arqueológica, sendo construída exclusivamente com base nas fontes textuais e, segundo eles, comprometendo as pesquisas subsequentes. Os primeiros pesquisadores (dentre os quais, arqueólogos) tomaram as concordâncias existentes entre as fontes clássicas e os grandes manuscritos da caverna 1, como a ideia de um grupo asceta no deserto, o isolamento social, e o conjunto de práticas disciplinadas, como elementos que se adequariam à disposição dos edifícios e ao posicionamento do assentamento.

Há outros questionamentos mais pontuais. No que se refere a esse plano arquitetônico citado acima, parte dos arqueólogos insiste que ele definitivamente não condiz com o de uma comunidade asceta, pois sua estrutura seria similar com a de outros assentamentos do período criados 12 Para uma reconstrução virtual de todo o sítio, veja: virtualqumran.huji.ac.il (último
acesso: 22/01/2020).

Heródoto, Unifesp, Guarulhos, v. 4, n. 2, 2019.2 p. 283-305

DOI: $10.34024 /$ herodoto.2019.v4.10976 
com fins militares ou industriais. Outra ideia, normalmente associada à do ascetismo, é a do celibato masculino. O cemitério adjacente ao sítio, ao contrário, não colabora com a conclusão extraída das fontes textuais sobre um grupo celibatário, ${ }^{13}$ pois foram encontrados túmulos com corpos de mulheres e crianças. Também os milhares de objetos de cerâmica, a argila, as várias piscinas e fornos no sítio, não colaboram com a tese de um grupo religioso letrado naquelas dependências. ${ }^{14} \mathrm{~A}$ mais importante evidência textual utilizada para defender a hipótese do grupo dos manuscritos em Qumran é a descrição de Plínio. Ela também possui falhas que foram apontadas pelos arqueólogos. Sua obra, História Natural, foi escrita durante a década de 70 d.C., quando o assentamento de Qumran já havia sido destruído. Seu relato é em primeira pessoa e em tempo presente. Ou seja, Plínio falou de algo que não conheceu. ${ }^{15}$

\footnotetext{
$13 \mathrm{Na}$ verdade, as fontes textuais também não são unânimes quanto a isso (Guerra Judaica 2.8.13).

${ }^{14} \mathrm{O}$ jarro descoberto por de Vaux no assentamento, parecido com os que se encontravam nas cavernas (e por isso chamado de "jarro de manuscritos"), deu origem a um debate que permanece até os dias atuais, particular ao campo da Arqueologia, mas que divide os arqueólogos (Magen, Peleg, 2007; Mizzi, 2017).

15 Plínio comete um erro em sua descrição, confundindo a cidade de Jericó com Jerusalém. Esse equívoco cometido por Plínio e sua descrição como fonte secundária são, para alguns pesquisadores, as provas de que a fonte textual mais objetiva é corrompida.
}

Heródoto, Unifesp, Guarulhos, v. 4, n. 2, 2019.2 p. 283-305

DOI: $10.34024 /$ herodoto.2019.v4.10976 


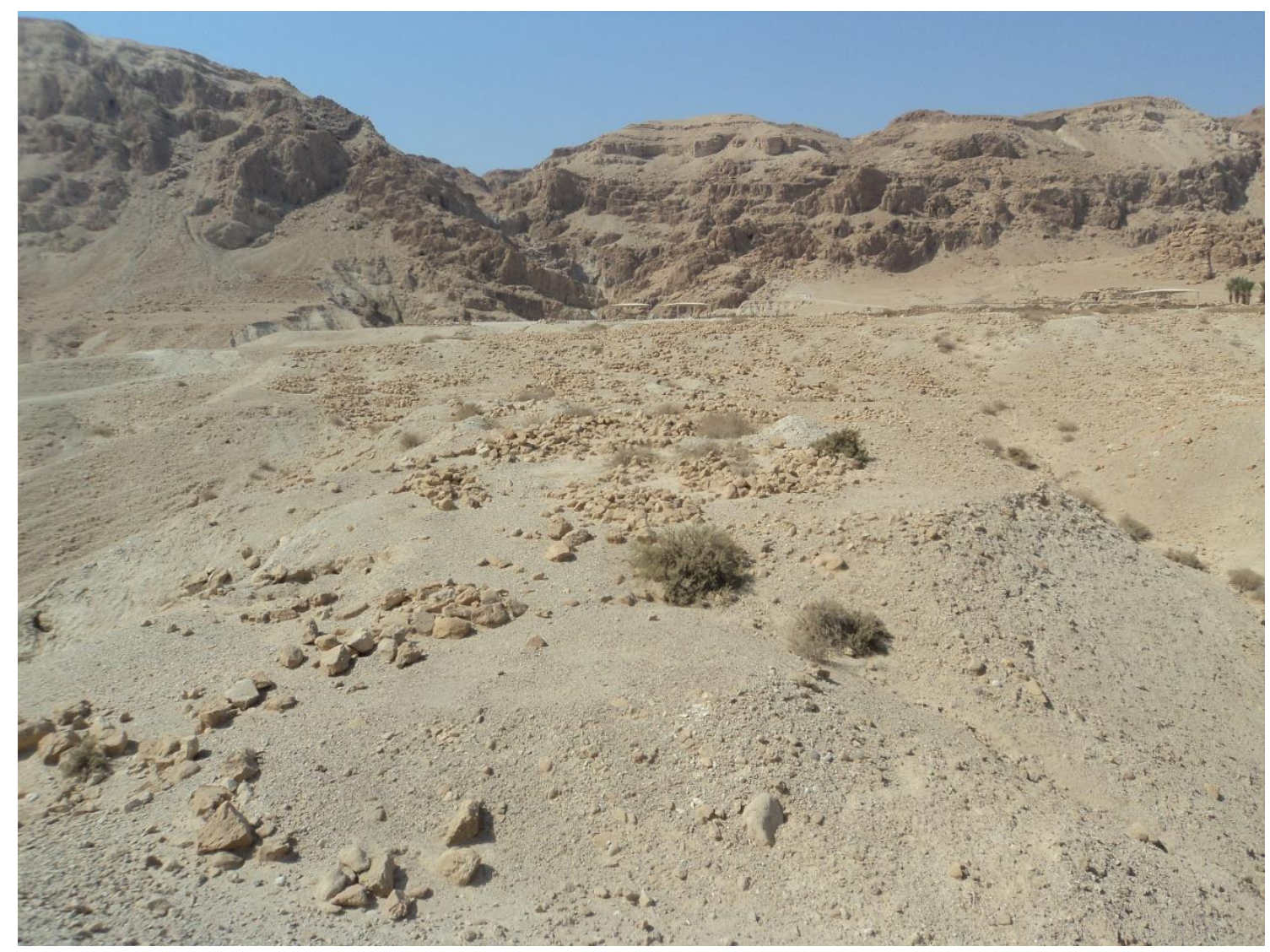

Figura 4: Cemitério, a leste do assentamento (ao fundo). São mais de mil túmulos. Os do período dos manuscritos possuem esqueletos de mulheres e provavelmente soldados de guerra (arquivo pessoal).

A Arqueologia, ao contrário da História, tem promovido um debate bem mais intenso e produtivo sobre o contexto material dos Manuscritos de Qumran. Se entre os arqueólogos existe uma diversidade de hipóteses para explicar os manuscritos e o assentamento, os historiadores pouco se aventuraram em discutir com profundidade o conjunto das fontes materiais bem como pouco aproveitaram desses debates desde as primeiras contestações à tríade de Qumran. É bem mais comum encontrar entre eles a assertiva de que Qumran foi produto de um grupo religioso judaico-essênio que redigiu manuscritos e os depositou nas cavernas próximas quando ciente do iminente conflito com os romanos. Em outros momentos, a estratégia empregada pelos historiadores é a de simplesmente se afastar desse tema tão controverso nas investigações. É bastante comum, na introdução de seus trabalhos, encontrar: "partimos do posicionamento de que a seita dos essênios, que redigiu os manuscritos, residiu em Qumran" (recurso que o presente autor admite já ter utilizado). Assim, sem uma consideração pormenorizada, suas teses são alicerçadas nesse paradigma. 
O que explicaria essa negligência dos historiadores para com esse debate? Enfim, é, para os historiadores, fundamental posicionar geograficamente o local em que os manuscritos foram produzidos e o grupo que os deteve? Muitas temáticas exploradas pelos historiadores se concentram apenas nas fontes textuais e relegam outro tipo de contextualização. Outras, na verdade, apresentariam pouca ou nenhuma contribuição se recorressem aos estudos sobre cultura material. Por exemplo, pesquisas que se ocupam com a paleografia entre os séculos II a.C. e I d.C. ou da evolução do texto da Bíblia Hebraica se utilizam basicamente do contexto literário dos manuscritos. Mesmo as pesquisas que se dedicam em analisar o papel social dos grupos político-religiosos judaicos, podem, desde que utilizadas as ferramentas metodológicas apropriadas, se abster da necessidade de colocar os manuscritos nas mãos de um grupo e em local específicos. Contudo, a possibilidade de se eximir da discussão sobre a localização geográfica dos manuscritos e de Qumran é restrita a um número limitado de temáticas. Aquelas que tratam da economia, da legislação interna, dos atritos político-religiosos, da formação histórica do grupo redator dos manuscritos, e tantos outros temas comuns nos estudos históricos, dificilmente podem abdicar de uma base de sustentação e acabam por recorrer à tríade de Qumran.

Se houve algum reposicionamento nas concepções espaciais sobre os manuscritos e Qumran por parte dos historiadores, ele se deveu mais ao desenvolvimento dos estudos literários do que às contribuições dos arqueólogos. Os estudos sobre dois dos mais famosos manuscritos encontrados em Qumran, a Regra da Comunidade (1QS) e o Documento de Damasco (CD), mostram que não houve apenas um grupo que esteve sob a autoridade dos manuscritos, mas vários e dispersos por locais diferentes durante o mesmo período histórico. Cross, com base nesses textos, havia delineado os primeiros esboços sobre a fragmentação dos essênios mesmo antes de Rengstorf promover a primeira contestação (1958). Décadas depois, essa opinião já estaria mais bem elaborada e canonizada entre os historiadores. O historiador bíblico Geza Vermes, por exemplo, afirmou que Qumran foi um "centro essênio", que reunia todos os acampamentos essênios em épocas de festividades (1997: 72-73). Entre seus efeitos, esse esforço epistemológico promoveu ao longo do tempo uma remodelação dos conceitos utilizados para se referir aos autores dos manuscritos, como yahad e 'edah (nomes próprios, encontrados respectivamente em 1QS e CD), ou "comunidade dos manuscritos" ou "grupo" (termo bastante neutro, de orientação socioantropológica) - conceitos que, em geral, enfraquecem a 
necessidade de associação dos manuscritos com um local específico (embora não abdiquem da tríade de Qumran).16

\section{Os problemas epistemológicos entre a Arqueologia e a História}

Aponto, neste momento, o que acredito ser o maior obstáculo para a conjugação das hipóteses sobre os manuscritos e Qumran: a supervalorização das fontes que seriam "particulares" a cada campo de estudos - as fontes textuais como algo exclusivo da História e as materiais como exclusivas da Arqueologia. Esses dois conjuntos documentais parecem guiar historiadores e arqueólogos para caminhos contrários. Esse tema compartilhado por essas disciplinas reproduz o quadro de oposição da segunda metade do século XIX e que sobreviveu por décadas no século XX, em que tanto para a História quanto para a Arqueologia, as fontes só poderiam ser lidas e interpretadas por aqueles que seriam profissionais em suas respectivas disciplinas (Funari, 2008).

Partindo do ponto de vista de um historiador, utilizo o caso particular da disciplina História para entender a parcimônia dos historiadores quanto à seleção das fontes. As fontes materiais são, muitas vezes, utilizadas como recurso quando da ausência de material textual. Essa prática foi tão intensa até o século passado que até os dias de hoje presenciamos os resquícios do postulado "Arqueologia como disciplina auxiliar da História". A História desconsiderou por décadas os avanços científicos da Arqueologia e mesmo depois que os historiadores se conscientizaram da importância da utilização das fontes materiais, faltou a eles o conhecimento dos métodos, técnicas e abordagens particulares à Arqueologia. As mudanças com pesquisadores independentes pós-positivistas e com os annales viriam a modificar positivamente esse quadro e promover avanços nas pesquisas dos historiadores (Funari, 2008: 84-93). ${ }^{17}$

O diálogo interdisciplinar que promoveu essa reformulação das fontes resultou também no compartilhamento de muitos objetos, pois, como o objetivo das duas ciências é principalmente compreender as sociedades do

\footnotetext{
16 Outro resultado que discretamente aproximou historiadores dos arqueólogos foi a certeza de que ao menos parte dos manuscritos foi produzida em lugares desconhecidos e levados para a "comunidade de Qumran" (Schofield, 2009: 42-47).

${ }_{17}$ Foi o annale Marc Bloch que contribuiu com esse marco com a máxima tudo quanto o homem diz ou escreve, tudo quanto fabrica, tudo em que toca, pede e deve informar a seu respeito (2001 [1949]: 79). Tais perspectivas seriam extensamente aplicadas já pela "geração" posterior, com destaque à monumental produção realizada por Fernand Braudel.
}

Heródoto, Unifesp, Guarulhos, v. 4, n. 2, 2019.2 p. 283-305

DOI: $10.34024 /$ herodoto.2019.v4.10976 
passado, uma pode ser usada para complementar ou ratificar as conclusões da outra (Guarinello, 2011: 161). Faço uma digressão proposital que pode ilustrar isso, tomando como exemplo uma tradição israelita, considerada por muito tempo exclusivamente pelos historiadores. A cultura israelita é resultante de uma mescla de elementos culturais diversos e por isso fala-se muito que tais elementos coexistiram por séculos, mas que não teriam sido registrados por escrito pela elite sacerdotal por esta desempenhar uma ampla reforma político-religiosa a serviço da monarquia (nos séculos VIII a.C. e VII a.C., principalmente). A ideia de sincretismo, corretamente defendida pelos historiadores, foi aplicada a praticamente todos os aspectos dessa sociedade, principalmente em cultura e religião. Isso fez com que parte da tradição bíblica como a da abstenção do consumo da carne de porco (tabus alimentares) fosse também relativizada, já que o texto bíblico representaria apenas o viés do poder político monopolista que afirmava, no momento da reforma, que ela não deveria ser consumida. Ou seja, a carne de porco podia estar sendo consumida por determinados segmentos da população, mas as fontes textuais, a serviço da monarquia, omitiam essa prática. A Arqueologia viria a confirmar que a tradição bíblica presente nas fontes literárias estava correta e demonstrou aos historiadores que o princípio do sincretismo cultural não deveria ser aplicado a todos os aspectos daquela sociedade. O consumo da carne de porco era corrente entre os grupos cananeus, mas com a tomada paulatina de seus territórios pelos hebreus (séculos XI a.C. e $X$ a.C.) não são encontrados mais vestígios da criação de porcos naquelas regiões. Nesse exemplo, a convergência entre as fontes textuais e materiais fizeram com que a História e Arqueologia andassem de "mãos dadas", com informações completadas entre uma e outra.

Se em muitos casos as fontes textuais e materiais convergiram, promovendo uma relação consensual entre historiadores e arqueólogos na análise de determinados objetos, em outros, essa relação foi dissonante principalmente quando a Arqueologia provou que conclusões comuns aos historiadores eram equivocadas por não possuírem correspondências materiais ou serem incoerentes com os contextos históricos apontados. É isso o que ocorreu quando a Arqueologia afirmou que o conhecido relato de Flávio Josefo, o "suicídio de Massada", não possui qualquer evidência material que prove que ele tenha ocorrido - o que mostra mais um dos excessos de Josefo possíveis na literatura (Guerra Judaica 7.389-406). Isso também aconteceu quando a Arqueologia apontou para os anacronismos existentes na Bíblia Hebraica. São vários: narrativas que citam a criação de animais em locais que não possuem comprovação material, de cidades ou áreas povoadas que ainda não existiam no tempo em que as fontes textuais 
se referem, que os hebreus, como povo, não se formaram fora do que seria a Terra de Israel e sim dentro do próprio território e da miscigenação com populações locais etc (Finkelstein, 2018).

Não diferente dos casos citados acima, o procedimento inicial para se chegar a uma hipótese convergente sobre os manuscritos e Qumran tem sido correlacionar as fontes textuais e materiais. A valorização desproporcional de um conjunto documental, contudo, tem sido um problema (mais evidente entre os historiadores). Para a arqueóloga americana Jodi Magness (que é convencida pela tríade de Qumran), um dos grandes problemas dos arqueólogos é a priorização excessiva das evidências materiais em detrimento das fontes textuais. Questionando seu próprio campo, ela afirma que todas as fontes devem ser analisadas em conjunto visando uma complementação:

[...] sem os manuscritos os restos arqueológicos são ambíguos o bastante para oferecer uma variedade de interpretações possíveis: que Qumran é uma vila, casa senhorial, fortaleza, entreposto comercial, centro de fabricação de cerâmica, e assim por diante (2005: 3$)$.

Finley já nos avisara que a questão não é simplesmente correlacionar provas arqueológicas e literárias, mas usar a arqueologia para avaliar se, e até que ponto, a literatura tem algum valor (1989: 97). Esse conselho vai ao encontro do que dizem muitos arqueólogos ao pontuarem que a Arqueologia se faz presente também para corrigir os "excessos" das fontes literárias proporcionando um contraste importante ao mundo idealizado (e ideológico) dos textos, apresentando uma imagem que não foi alterada por florescimentos ou dinâmicas da memória cultural (Mizzi, 2017: 86).

No caso dos Manuscritos de Qumran, a complementação entre as fontes foi feita antes mesmo de o sítio ter sido escavado e, para os que criticam a hipótese inicial, isso fez com que as escavações e as interpretações sobre a cultura material fossem alinhadas com as interpretações extraídas das fontes textuais. Hirschfeld afirma que

a interpretação dos achados arqueológicos em concordância somente com os manuscritos, sem nenhuma comparação com um estudo arqueológico, poderia enganar o estudioso dentro de um círculo vicioso interpretativo em que os manuscritos explicam os achados e os achados explicam os manuscritos (2006: 225).

Como Hirschfeld, outros que não concordam com a tríade de Qumran negligenciam voluntariamente em correlacionar as fontes. Propõem, ao contrário, que o estudo de um conjunto documental deve ser feito sem a interferência de outro e que apenas em um segundo momento as 
conclusões extraídas de ambos sejam comparadas. Se esse procedimento é ou não acertado para os estudos dos manuscritos e Qumran, o fato é que se essa complementação entre as fontes não tiver lugar em qualquer momento da pesquisa, o resultado será a diminuição das possibilidades de criação de métodos e abordagens conjuntas também recue para a zona central de cada campo disciplinar - ou seja, para um espaço de epistemologia incipiente do ponto de vista interdisciplinar.

Essas discordâncias entre a História e a Arqueologia fazem com que ambas se afastem e reduzam as possibilidades de diálogo ao tratarem história social dos manuscritos e Qumran. Diante do quadro atual das interpretações, podemos questionar: é possível esperar que haja uma convergência entre as duas disciplinas? Da maneira como as pesquisas vêm sendo conduzidas, com forte concentração nas fontes, é possível que não. Parece, assim, que só será possível alguma mudança se novas descobertas forem feitas, sejam elas de textos ou artefatos, trazendo um material complementar. Mas isso, sabemos, é muito difícil ocorrer!

Outros pesquisadores, cientes dos limites de interpretação das fontes, sugerem que a alternativa seja mudar os métodos e abordagens. JeanBaptiste Humbert, por exemplo, sugere que se deva procurar quais as características religiosas ou seculares presentes no sítio com base em princípios da antropologia (2006: 19). Dennis Mizzi tem destacado a importância de se levarem os manuscritos "de volta às cavernas", para que o contexto arqueológico seja recriado e possam ser analisados como parte de um todo, sem que sejam mais priorizados que os artefatos (2017: 93) - ou seja, "transformar" os manuscritos em artefatos, pertencentes àquele sítio arqueológico. Eu defendo a ideia de que alguns conceitos que são utilizados para se pensar o contexto social dos manuscritos dificultam as interpretações, como por exemplo, o conceito "seita", utilizado tanto por arqueólogos quanto por historiadores. A palavra é bastante inadequada para se referir a um grupo religioso do período (e talvez a qualquer outro de qualquer outro período), pois está carregada negativamente por princípios construídos pelo cristianismo histórico. Aplicada aos manuscritos, reforça a ideia de que o grupo era apartado de relações com a sociedade e que Qumran seria assim um local alijado da cultura social e material que poderia apresentar traços comuns, por exemplo, em suas edificações. Ou seja, se houve ali um grupo religioso que escreveu os Manuscritos de Qumran, por que ele não poderia se utilizar dos mesmos elementos arquitetônicos disponíveis daquela sociedade? Por que ele não poderia ter sido um grupo religioso que teve uma atividade industrial? Se pensarmos o grupo dos manuscritos como seita, é muito possível que 
iremos concebê-los como ascetas, celibatários, habitantes do deserto, pobres materialmente e com uma vida de austeridades.

Ao final, percebemos que há uma região de fronteiras disciplinares em que as relações são insuficientes devido as fontes textuais e materiais exercem uma força centrípeta, que dificulta a criação de métodos e abordagens em comum - resultando, ao final, na criação e manutenção de "paradigmas científicos rivais" (utilizando o princípio de Cardoso [1997]). Penso que, a menos que os métodos e abordagens sejam revistos, será impossível comungar os esforços da História e da Arqueologia. Não seria absurdo pensar na possibilidade de criação de um método específico, oriundo das pesquisas dos manuscritos e de Qumran. Por si próprios, os estudos dos manuscritos forçaram a criação de (mais que métodos) ciências específicas, como a Codicologia antiga (que compreende no estudo de pergaminhos ou papiro em formato de códice) e no aprofundamento de outras, como a Paleografia. Caso consigamos superar o "diálogo de surdos" (redirecionando o debate braudeliano para a História e a Arqueologia) que permanece ainda hoje nos estudos dos manuscritos e Qumran, poderemos avançar ainda mais nesse campo extremamente profícuo de pesquisas em Antiguidade.

\section{Conclusões}

Meu objetivo aqui foi modesto frente a grandiosidade do problema: produzir um trabalho historiográfico com os principais marcos dos embates entre a História e a Arqueologia acerca da relação entre os Manuscritos de Qumran e o assentamento em Qumran e, ao final, propor uma pequena contribuição que se localiza no campo epistemológico. De maneira alguma, penso em esboçar um encerramento para um debate tão amplo que se mantém há décadas e que envolve inúmeros pesquisadores de ciências diversas.

Vemos na historiografia dos manuscritos que historiadores e arqueólogos têm se mantido demasiadamente dependentes das fontes às quais estão mais bem qualificados para considerar. A ausência de uma suposta "fonte-chave", que pudesse ser considerada "definitiva" (que parece existir, contudo não é reconhecida pelo outro), é o motivo que faz com eles recuem no diálogo interdisciplinar, inviabilizando a elaboração de novos métodos e novas abordagens complementares. A oposição foi tão bem mantida ao longo do tempo que os avanços teórico-metodológicos, patrocinados por diversas correntes historiográficas, e o desenvolvimento 
de novas tecnologias que pressionaram por mudanças na construção do saber científico, foram pouco compartilhados no campo de estudos dos manuscritos e Qumran por terem sido utilizados de forma restrita por cada disciplina.

Por fim, embora seja difícil estabelecer dados quantitativos precisos para mais de sete décadas de produção bibliográfica, uma análise panorâmica das principais propostas desde a descoberta dos manuscritos e as escavações em Qumran mostra que a vasta maioria dos historiadores é convencido pela tríade de Qumran. Já entre os arqueólogos há uma pluralidade de hipóteses - além de haver mais arqueólogos que se convenceram com fontes textuais do que historiadores que se convenceram pelas fontes materiais. Essa convicção desproporcional, por um lado, e o problema considerado inacabado e continuamente revisitado, por outro, compõem a tônica do embate mais caro nos 70 anos de historiografia dos Manuscritos de Qumran.

\section{Referências Bibliográficas}

Fontes Primárias

BÍBLIA DE JERUSALÉM. São Paulo: Paulinas, 1995.

GARCIA MARTÍNEZ, F. Textos de Qumran, Edição Fiel e Completa dos Documentos do Mar Morto. Trad. Valmor da Silva. Petrópolis: Vozes, 1995.

PLINY. Natural History. Trad. para o inglês de H. Rackham. Edição bilíngüe latim/inglês. Cambridge: Christ's College, 1947.

WHISTON, Whinston. Josephus: The complete works. Nashville: Thomas Nelson Incorporated, 2003.

YONGE, Charles Duke. The works of Philo: Complete and Unabridged (New updated Edition). Peabody, MA: Hendrickson Publishers, 1991.

Bibliografia

BLOCH, Marc. Apologia da História ou oficio do historiador. Trad. André Telles. Rio de Janeiro: Jorge Zahar Ed, 2001.

BRAUDEL, Fernand. Histoire et Sciences Sociales: la Longue Durée. Annales, v. 13, n. 4, p. 725-753, 1958. 
CARDOSO, Ciro Flamarion. História e paradigmas rivais. In: VAINFAS, Ronaldo. Domínios da História. Rio de Janeiro: Campus, 1997.

CROSS, Frank M. Canaanite Myth and Hebrew Epic: Essays in the History of the Religion of Israel. Cambridge, MA: Harvard University, 1973.

. The Ancient Library of Qumran and Modern Biblical Studies. New York: Doubleday \& Co., 1958.

DAVIES, Philip R. The prehistory of Qumran. In: The Dead Sea Scrolls: Forty years of Research. Leiden: Brill, 1992.

DONCEEL, Robert. DONCEEL-VOUTE, Pauline. The archaeology of Khirbet Qumran. In: Wise, Michael O. (et al). Methods of Investigation of the Dead Sea Scrolls and the Khirbet Qumran Site: present realities and future prospects. New York: New York Academic Sciences, 1994.

FINKELSTEIN, Israel. O reino esquecido: Arqueologia e História de Israel Norte. Trad. Silas Klein Cardoso; Élcio Valmiro Sales de Mendonça. São Paulo: Paulus, 2015.

Silberman, Neil A. A Bíblia desenterrada: a nova visão arqueológica do antigo Israel e das origens dos seus textos sagrados. São Paulo: Vozes, 2018.

FINLEY, Moses I. Arqueologia e história. In: O uso e abuso da História. São Paulo: Martins Fontes, 1989.

FUNARI, Pedro Paulo A. Os historiadores e a cultura material. In: PINSKY, Carla Bassanezi (org.). Fontes Históricas. São Paulo: Contexto, 2008.

GOLB, Nornan. Who hid the Dead Sea Scrolls? Biblical Archaeologist. The American Schools of Oriental Research. v. 48, n. 2, p. 68-82, 1985.

GUARINELLO, Norberto L. Arqueologia e cultura material: um pequeno ensaio. In: Bruno, M.C.O. Cerqueira, F.V. Funari P.P.A. Arqueologia do Mediterrâneo Antigo: Estudos em homenagem a Haiganuch Sarian. São Paulo, 2011.

GRATZFELD, Gaudêncio. Novo rumo na investigação qumrânica. Revista de Cultura Bíblica, São Paulo, v. 5, n. 20, 1961.

HIRSCHFELD, Yizhar. Qumran in Context: Reassessing the Archaeological Evidence. Massachusetts: Hendrickson, 2004. 
Qumran in the Second Temple Period: A Reassessment. In: Galor, K. Humbert, J.B. Zangenberg, J. (eds). Qumran, The Site of the Dead Sea Scrolls: Archaeological Interpretations and Debates Proceedings of a Conference held at Brown University, November 17-19, 2002. Leiden: Brill, 2006.

HUMBERT, Jean-Babtiste. Some remarks on the Archaeology of Qumran. In: Galor, K. Humbert, J.B. Zangenberg, J. (eds). Qumran, The Site of the Dead Sea Scrolls: Archaeological Interpretations and Debates Proceedings of a Conference held at Brown University, November 17-19, 2002. Leiden: Brill, 2006.

MAGEN, Yitzahak. Peleg, Yuval. The Qumran excavation, 1993-2004: preliminary report. Jerusalem: Staff Officer of Archaeology, 2007.

MAGNESS, Jody. Hirschfeld, Yitzar, Qumran in Context: Reassessing the Archaeological Evidence. RBL, v. 8. 2005.

. The Archaeology of Qumran and the Dead Sea Scrolls. Grand Rapids: Eerdmans, 2002.

MIZZI, Dennis. Qumran aos setenta: algumas reflexões sobre os setenta anos da pesquisa acadêmica sobre a Arqueologia de Qumran e os Manuscritos do Mar Morto. In. VIEIRA, Fernando Mattiolli (org.). Os Manuscritos do Mar Morto: 70 anos da Descoberta. São Paulo: Humanitas, 2017.

RENGSTORF, Karl H. Hirbet Qumran und die Bibliothek von Toten Meer. Stuttgart: Kohlhammer, 1960.

SCHNIEDEWIND, William. M. Como a Bíblia tornou-se um livro. Trad. Luciana Pudenzi. São Paulo: Loyola, 2011.

SCHOFIELD, Alison. From Qumran to the Yahad: a new paradigm of textual development for the Community Rule. Leiden: Brill, 2009.

SHANKS, Herschel (org.). Para compreender os manuscritos do mar Morto. Trad. Laura Rumchinsky. Rio de Janeiro: Imago, 1993.

SUKENIK, Eleazar L. Megilloth Genuzoth (hebraico). Jerusalém: Mosad Bialik, 1948.

VAUX, Roland de. Archaeology and the Dead Sea Scrolls. London: Oxford University Press, 1973. 
.'Fouille de Khirbet Qumrân: rapport préliminaire', Revue Biblique 60: 83-106, 1953.

VERMES, Geza. Os Manuscritos do Mar Morto. Trad. Júlia Bárány; Maria H. de O. Tricca. São Paulo: Mercúryo, 1997.

VIEIRA, Fernando Mattiolli (org.). Os Manuscritos do Mar Morto: 70 anos da Descoberta. São Paulo: Humanitas, 2017. 